\title{
Acupuncture points and perforating cutaneous vessels identified in the upper limb using infrared thermography
}

\author{
Filipa Soares-Parreira ${ }^{1}$ David Álvarez-Prats ${ }^{2,5}$ Óscar Carvajal-Fernández ${ }^{2}$ Marcelo Barbosa-Pereira ${ }^{4}$ \\ Fermín Valera-Garrido 4,5
}

${ }^{1}$ Clínica Fisioefe (Fisioterapia e Bem Estar), Espargo, Portugal

${ }^{2}$ Clínica Fisioterapia Océano, Madrid, Spain

${ }^{3}$ Clínica FisioOn (Fisioterapia \& Saúde Integral), Amarante Portugal

${ }^{4}$ MVClinic Institute, Madrid, Spain

${ }^{5}$ Department of Physiotherapy, CEU San Pablo University, Madrid, Spain

Rev Fisioter Invasiva 2020;3:7-12.

\author{
Address for correspondence Filipa Soares Parreira, MSc, Clínica \\ Fisioefe (Fisioterapia e Bem Estar), Rua Nossa Senhora de Fátima, 40, \\ loja B4, 4520-110, Espargo, Portugal \\ (e-mail: filipa_parreira@hotmail.com).
}

\begin{abstract}
Keywords

- acupuncture

- acupuncture points

- infrared thermography

- perforating cutaneous vessel

Objective To verify the presence of perforating cutaneous vessels (PCV) among different acupuncture points (AP) of the upper limb by means of infrared thermography (IT).

Material and Methods An analytical observational cross-sectional study examining the upper limb of volunteer subjects $(n=7)$. A total of 91 AP were analyzed, as well as 91 control points (CP), one for each AP. In each subject, first, the AP and their corresponding $\mathrm{CP}$ were marked and, second, the thermographic images were taken. The images were then processed using the Physio Thermal Imaging (PTI) software, observing the presence or absence of these PCV on the AP and corresponding CP.

Results PCV were identified in $68.1 \%$ of the total 91 AP examined. However, despite the strong trend in the presence of PCV in the studied AP, certain AP did not display significant differences with their corresponding $C P$.

Conclusions This study shows a certain correlation between the PCV and the AP chosen in this sample, due to the high presence of PCV in the AP. IT is a useful tool during physical therapy treatment procedures using acupuncture.
\end{abstract}

\section{Introduction}

Acupuncture is one of the main pillars of traditional medicine in the Western Pacific region and in recent decades has become a comprehensive therapeutic method with high effectiveness in the control of multiple body disorders and pathologies. ${ }^{1,2}$ Despite this, many of its therapeutic effects are questioned, as in the field of pain management where its analgesic effects are under debate. ${ }^{3}$ However, authors such as Svedberg et al., ${ }^{4}$ state that acupuncture activates an opioidmediated analgesic action pathway and that, combined with the alteration of sympathetic activity, generates changes in skin temperature, through vasodilation and/or vasoconstriction mechanisms. In addition, the anatomical study of meridians and acupuncture points (AP), as well as the associated biomechanisms, are the focus of extensive research in the field of acupuncture among the scientific community. ${ }^{5}$ At present, various hypotheses are proposed on the effects of acupuncture and its relationship with the activity of the sympathetic nervous system, the endocrine system and the immune system. ${ }^{6}$ Although its use is widespread and it is practiced worldwide, as discussed above, these effects have not yet been fully scientifically validated. For these reasons, there is a need to more specifically evaluate its effectiveness received

May 2, 2020

accepted

May 22, 2020
DOI https://doi.org/

10.1055/s-0040-1713821. ISSN 2386-4591.
Copyright ( $\odot 2020$ by Thieme Revinter

Publicações Ltda, Rio de Janeiro, Brazil
License terms

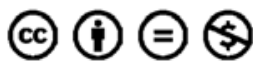


and mechanism of action, ${ }^{7}$ by introducing new assessment and measurement tools in an attempt to relate AP to different body structures and thus be able to more fully understand the functioning of these points.

Moreover, this study takes into account the so-called perforating cutaneous vessels (PCV). These are relevant vascular structures in the field of microsurgery or plastic surgery, especially in relation to skin grafting and reimplantation techniques. ${ }^{8,9}$

A PCV is defined as a final vessel that originates from one of the axial vessels of the body and passes through certain structural elements (fascia, muscle septa...) until it becomes subcutaneous. ${ }^{9,10}$ In the literature there are different methods for locating PCV, such as hand doppler, color doppler ultrasound, angiographic computerized thermography, angiographic magnetic resonance and infrared thermography (IT). ${ }^{11,12}$

In relation to the latter, some authors state that the use of IT in the field of acupuncture is decisive in verifying the possible existence of the meridians and the thermal reactions of the skin derived from the insertion of the needle. ${ }^{13}$

Thus, IT is a complementary test, validated by the FDA (Food and Drug Administration) in 1982, which is noninvasive and non-radiating, with a high sensitivity, capable of capturing the infrared radiation emitted by the body and analyzing the physiological functions related to the control of skin temperature. ${ }^{14}$ This instrument detects the infrared light emitted by the body. ${ }^{15}$ The skin temperature is proportional to the cutaneous blood flow, hence the important relationship between both concepts. ${ }^{14}$ IT is a complementary imaging method that does not show anatomical abnormalities, but is capable of showing physiological changes. ${ }^{16}$ Thus, in areas of higher cutaneous blood flow, the temperature will be higher than in areas of lower cutaneous blood flow. ${ }^{16}$

Hence, the use of IT in the present study will allow us to accurately observe the location of the PCV in the form of 'hot spots' or points of higher temperature in relation to the surrounding tissue in certain acclimatization situations. Our aim was to determine the association between upper limb AP and PCV, using IT to identify the PCV.

\section{Material and Methods}

\section{Design}

An analytical observational cross-sectional study was performed, in which the presence of PCV was identified using IT over a series of 7 AP and 7 Control Points (CP) which were previously identified in both sides of the body by two physical therapists experienced in the field of IT and invasive physical therapy. The Research Ethics Committee of the CEU São Pablo University approved the study, which complies with the principles established in the Declaration of Helsinki.

\section{Sample}

The study participants were 7 subjects ( 3 women and 4 men) with an average age of 35 years (range 25-53) recruited among patients of the FisioOn-Fisioterapia \& Saúde Integral clinic (Santa María da Feira-Portugal), who signed the corresponding informed consent to participate in the study. The exclusion criteria were the presence of systemic pathologies and/or taking substances and/or drugs that could change the normal physiological behavior of the nervous system and therefore could cause alterations in the cutaneous vascular flow.

\section{Measurements Performed}

The variables were the AP and their respective $\mathrm{CP}$, which were systematically located within the same meridian at two centimeters cranial or caudal to their corresponding AP, so that in the area selected as a CP, no AP were described.

The first physical therapist (PT) was in charge of measuring and locating the different $\mathrm{AP}$ and $\mathrm{CP}$, as well as taking thermographic images. The second physical therapist (DA) was responsible for the computer processing of the thermographic images and the analyzing the results obtained. The 7 selected AP were located on the anterolateral side of the arm within the large intestine meridian (LI12, LI13, LI14, LI15) and on the anterior side within the lung meridian (LU3, LU4 and LU5) (-Table 1).

It should be noted that the acupuncture point LI11, only served as an auxiliary point for the rest of the measurements, since its CP was included in the forearm and was therefore outside the thermographic capture area.

A total of $7 \mathrm{AP}$ and $7 \mathrm{CP}$ located in both hemispheres were located in each subject using the "ruler" method. The "ruler" method is the most precise method according to different studies in relation to AP location. It consists of assigning to the Chinese measure known as "cun", which is the most widely used measure in the acupuncture atlas and in clinical practice, and whose value is proportional to the measurement of the first phalanx of the first finger, a value in centimeters that is

Table 1 Description of the AP used in the study

\begin{tabular}{|c|c|c|}
\hline Point & Meridian & Measurement procedure \\
\hline LI11 & $\begin{array}{l}\text { Large } \\
\text { intestine }\end{array}$ & $\begin{array}{l}\text { Elbow flexed to } 90^{\circ} \text {, between the } \\
\text { lateral side of the joint articular line } \\
\text { of the elbow (elbow crease) and the } \\
\text { radial epicondyle of the humerus. On } \\
\text { the extensor carpi radialis longus } \\
\text { (ECRL) }\end{array}$ \\
\hline LI12 & $\begin{array}{l}\text { Large } \\
\text { intestine }\end{array}$ & $\begin{array}{l}1 \text { cun superior to LI11 (anterior bor- } \\
\text { der of the humerus) }\end{array}$ \\
\hline LI13 & $\begin{array}{l}\text { Large } \\
\text { intestine }\end{array}$ & $\begin{array}{l}3 \text { cun superior to LI11 (lateral border } \\
\text { of the biceps) }\end{array}$ \\
\hline LI14 & $\begin{array}{l}\text { Large } \\
\text { intestine }\end{array}$ & $\begin{array}{l}7 \text { cun superior to LI11 (depression in } \\
\text { the insertion area of the lower tip of } \\
\text { the deltoid muscle) }\end{array}$ \\
\hline LI15 & $\begin{array}{l}\text { Large } \\
\text { intestine }\end{array}$ & $\begin{array}{l}\text { Anterior and inferior depression of } \\
\text { the acromion }\end{array}$ \\
\hline LU3 & Lung & $\begin{array}{l}3 \text { cun below the inferior to the ante- } \\
\text { rior axillary fold on the sulcus of the } \\
\text { lateral border of the biceps brachii } \\
\text { muscle }\end{array}$ \\
\hline LU4 & Lung & 1 cun below LU 3 \\
\hline LU5 & Lung & $\begin{array}{l}\text { Elbow cubital crease, radial depres- } \\
\text { sion of the biceps brachii tendon }\end{array}$ \\
\hline
\end{tabular}


individualized for each subject and each side of the body, obtaining a final precision area for the location of the AP of $2.90 \mathrm{~cm}^{2} \cdot{ }^{17,18}$ This area has been used in the present study as a reference area for AP and CP to validate the presence of PCV.

To obtain the individual value of a "cun," a metric measurement was first made using a tape measure from the midpoint of the wrist crease to the lateral epicondyle of the forearm of each side of the body. ${ }^{18}$ This average value was then divided by 12 "cuns," which is the "cun" measurement reported in the various acupuncture atlases. ${ }^{18}$ In this manner, we obtained the value of a "cun" in centimeters for each side of the body and in each individual.

Finally, the different AP and CP were marked as described in - Table 1, with the measurements obtained and using a precision area of $2.90 \mathrm{~cm}^{2}$ as described in the "ruler" method. The patient's body was then marked using a template, with a diameter of $2.90 \mathrm{~cm}^{2}$. Thus, the AP and CP were marked using a pen with metallic ink ("EDDING"). The CP were always marked $2.0 \mathrm{~cm}$ above or below each AP, following the imaginary line of the corresponding meridian and preventing it from coinciding with another AP.

For this analysis, all individuals were subjected to a 10minute acclimatization in a standing position with the minimum possible clothing on the upper body in a room with a temperature of $22^{\circ}-25^{\circ}$. A minimum period of 10 minutes is considered sufficient for the body to establish a thermal homeostasis and for the effects of thermoregulation to disappear. ${ }^{19,20}$

Once the subject was acclimatized, vascular stimulation was performed by means of a declined position with the lower limbs above heart level and the upper limbs at rest. This results in cutaneous vasodilation as a consequence of the activation of the veno-arteriolar reflex of the skin. ${ }^{21}$ The AP and CP were clearly identifiable on the thermal images thanks to the use of the metallic ink pen (-Fig. 1 ).

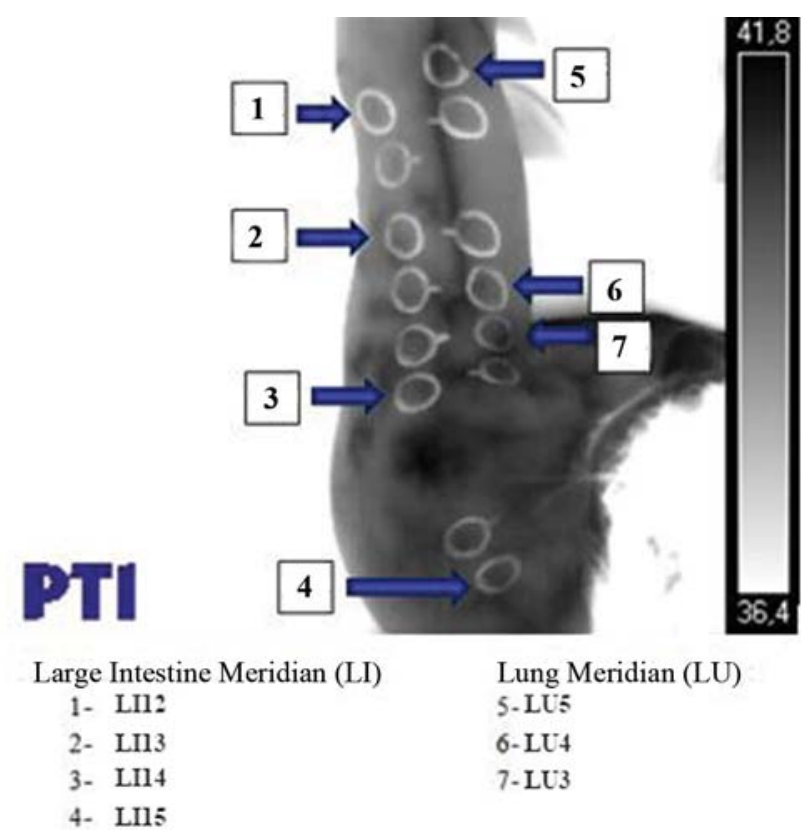

Fig. 1 Thermographic image showing the two meridians studied.
A Flir A65 thermographic camera (resolution $320 \times 240$; lens FOL1) was used to capture the images. These were subsequently processed using the Physio Thermal Imaging (PTI) software.

\section{Statistical Analysis}

The statistical analysis was performed using IBM SPSS Statistics ${ }^{\circledR}$ version 24.0 software, with a significance level of 0.05 .

To identify the existence of an association between the type of point (acupuncture/control) and whether it coincided with a perforating vessel (yes/no), the chi-square test or the Fisher test was used.

To quantify the association between these variables, the risk ratio and the odds ratio were used, as well as the respective $95 \%$ confidence intervals. These measures were considered significant when the confidence interval did not include the value 1 .

The calculation formulas used were:

$\mathrm{RR}=$ Probability of AP coinciding with perforating vessels/ Proportion of AP coinciding with PV;

$\mathrm{OR}=$ Odds of AP coinciding with perforating vessels/ Odds of AP coinciding with $\mathrm{CP}$.

\section{Results}

After analyzing all the AP and CP, significant differences were observed between these in relation to the proportion of points coinciding with the PCV $(p<0.001)$.

As shown on - Table 2, the percentage of AP that coincided with PCV was $68.1 \%$, compared with $41.8 \%$ for CP. This relationship is demonstrated by the risk ratio and odds ratio values and their confidence intervals (95\% CI). Thus, we verified that in the AP the probability (risk) of coinciding with the PCV was $1.63[1.23 ; 2.16]$ times greater to the probability for the CP. Similarly, the odds ratio revealed that the risk (odds) of coinciding with a PCV was 2.98 [1.63, 5.47] times higher than the $\mathrm{CP}$.

When the different points were analyzed individually, the association between the type of AP and CP and the overlapping of these points was only verified at acupuncture points LU5 ( $p<0.001)$ and LU4 $(p=0.018)$. At point LU5, we were unable to calculate the risk and the odds because $100 \%$ and $0 \%$ of coinciding points were observed, respectively, for the AP and CP. At LU4 it the probability (risk) of coinciding with the PCV was $2.50[1.05 ; 5.96]$ times higher than the probability of coinciding with the CP. Furthermore, in the AP the opportunity (quota) of coinciding with the perforating vessels was $7.50[1.31 ; 43.03]$ times higher than that of the CP. At point LI15, despite a similar trend, the data did not reach statistical significance, both in relation to the test value $(p=0.097)$, nor in relation to the CI (RR: $[0.98,3.45]$, $\mathrm{OR}=[1.00,41.21])$.

However, it should be noted that the lower $\mathrm{CI}$ values were very close to 1 . On the other points, no significant differences were observed between the proportions of the AP and CP coinciding with the PCV. 
Table 2 Differences in the frequency of PCV between the AP and CP

\begin{tabular}{|c|c|c|c|c|c|c|c|}
\hline & \multicolumn{2}{|c|}{ PCV coinciding point } & \multicolumn{2}{|c|}{ Proportion of risk } & \multicolumn{2}{|c|}{ Odds ratio } & \multirow{2}{*}{$\begin{array}{l}\text { Dif. Proportions } \\
\text { p-value }\end{array}$} \\
\hline & $\mathrm{AP}(n=13)$ & $\mathrm{CP}(n=13)$ & Value & {$[95 \% \mathrm{Cl}]$} & Value & {$[95 \% \mathrm{Cl}]$} & \\
\hline \multirow[t]{2}{*}{$\mathrm{LI} 12$} & 5 & 7 & \multirow[t]{2}{*}{0.71} & \multirow[t]{2}{*}[0.30;1.67]{} & \multirow[t]{2}{*}{0.54} & \multirow[t]{2}{*}[0.11;2.55]{} & \multirow[t]{2}{*}{$0.431^{\mathrm{a}}$} \\
\hline & $(38.5 \%)$ & (53.8\%) & & & & & \\
\hline \multirow[t]{2}{*}{ LI13 } & 8 & 9 & \multirow[t]{2}{*}{0.89} & \multirow[t]{2}{*}[0.51;1.56]{} & \multirow[t]{2}{*}{0.71} & \multirow[t]{2}{*}[0.14;3.61]{} & \multirow[t]{2}{*}{$1.000^{\mathrm{b}}$} \\
\hline & $(61.5 \%)$ & $(69.2 \%)$ & & & & & \\
\hline \multirow[t]{2}{*}{ LI14 } & 8 & 5 & \multirow[t]{2}{*}{1.60} & \multirow[t]{2}{*}[0.71;3.60]{} & \multirow[t]{2}{*}{2.56} & \multirow[t]{2}{*}[0.53;12.43]{} & \multirow[t]{2}{*}{$0.239^{a}$} \\
\hline & $(61.5 \%)$ & $(38.5 \%)$ & & & & & \\
\hline \multirow[t]{2}{*}{ LI15 } & 11 & 6 & \multirow[t]{2}{*}{1.83} & \multirow[t]{2}{*}[0.98;3.45]{} & \multirow[t]{2}{*}{6.42} & \multirow[t]{2}{*}[1.00;41.21]{} & \multirow[t]{2}{*}{$0.097^{b}$} \\
\hline & $(84.6 \%)$ & $(46.2 \%)$ & & & & & \\
\hline \multirow[t]{2}{*}{ LU5 } & 13 & 0 & \multirow[t]{2}{*}{ N.C } & \multirow[t]{2}{*}{ N.C } & \multirow[t]{2}{*}{ N.C } & \multirow[t]{2}{*}{ N.C } & \multirow[t]{2}{*}{$<0.001^{\mathrm{a}}$} \\
\hline & $(100.0 \%)$ & $(0.0 \%)$ & & & & & \\
\hline \multirow[t]{2}{*}{ LU4 } & 10 & 4 & \multirow[t]{2}{*}{${ }^{*} 2.50$} & {$[1.05 ; 5.96]$} & ${ }^{*} 7.50$ & {$[1.31 ; 43.03]$} & $0.018^{\mathrm{a}}$ \\
\hline & $(76.9 \%)$ & $(30.8 \%)$ & & & & & \\
\hline LU3 & 7 & 7 & 1.00 & {$[0.49 ; 2.04]$} & 1.00 & {$[0.21 ; 4.67]$} & $1.000^{\mathrm{a}}$ \\
\hline & $(53.8 \%)$ & $(53.8 \%)$ & & & & & \\
\hline All & 62 & 38 & ${ }^{*} 1.63$ & {$[1.23 ; 2.16]$} & ${ }^{*} 2.98$ & {$[1.63 ; 5.47]$} & $<0.001^{\mathrm{a}}$ \\
\hline & (68.1\%) & $(41.8 \%)$ & & & & & \\
\hline
\end{tabular}

Abbreviation: N.c, Not calculated.

a_Chi square test.

b- Fisher's test.

\section{Discussion}

The results of this study show that the probability of AP coinciding with a PCV is higher compared with CP. This finding is in line with the studies performed by $\mathrm{Wei}^{8}$ and Alvarez et al. ${ }^{22}$ which verified a high correlation between AP and $\mathrm{CP}$.

It is important to note that the AP of LU4 $(p=0.018)$, LU5 $(p<0.001)$ and the high AP trend of LI15 $(p=0.097)$ compared with their $C P$, showed a statistical difference in their coinciding with PCV. The AP that showed a strong statistical difference in coinciding with PCV are slightly less frequent compared with the other AP studied, due to the fact that they have been attenuated by the AP where there were no significant differences.

According to traditional acupuncture, AP are not static tissue structures, rather they are dynamic and are interconnected to the functional concepts of microcirculation and/or neuroendocrinology. An example of this is found in a study by Yang, ${ }^{23}$ who stated that the appearance of the same meridian or AP varies from one individual to another. Some individuals may even have the meridian line on the surface of their skin, others may have two or more lines of the same meridian, whereas others may have no obvious lines.

In addition, PCV are anatomical structures based on modern biomedicine and although they create connections between each other and pass through an axial line, which resembles a meridian path, in many situations they adopt separate paths throughout these. ${ }^{24,25}$ Despite these contradictions, if scientific evidence continues to establish rela- tionships between the two structures, it will be necessary to establish more studies in this line of research.

The advantage of IT is that it uses infrared radiation emitted by the subject's body. The highest and most clearly defined temperature zones are found after vascular stimulation processes, representing possible areas where PCV may be present. ${ }^{26}$ By visualizing the location of several PCV at the same time in a single image, IT poses a great advantage compared with other diagnostic methods. In processing the thermal images of the study, a qualitative analysis was used using PTI software based on an inverted gray scale where the PCV appear as black spots, with white representing low temperatures and black indicating high temperatures. ${ }^{23}$ In microsurgery, physicians use IT to identify the location of vessels clearly and visually, enabling the creation of skin grafts with a lower likelihood of necrosis, considering the presence of large PCV that will ensure the viability of these. $^{27}$

In the present study, for some of the AP, no significant differences were observed between the proportions of overlapping with PCV. This may be due to the size and length of a PCV. According to Kimura's research, ${ }^{28}$ the distribution of PCV has been extensively studied, however, the contribution of each PCV to perfusion is unknown, therefore further research into vascular skin tissue is needed.

The ability to differentiate between areas with PCV with rapid warming and areas with slower warming has important implications for the present study, as it did for the study conducted by Chubb. ${ }^{29}$ It can be assumed that this is due to variations in the underlying vascular tissue, and may 
contribute to possible biases in the results depending on the anatomical area of study. ${ }^{30}$

The results obtained through observation of AP and CP by taking images using IT depend on the specifications of the thermal imaging system, the individual characteristics of each subject, and the surrounding conditions of each individual, having observed that the presence of powerful subcutaneous venous vascular systems such as the cephalic and basilic vein, together with their variants in the area of study could have influenced the final result, which was not the case in their previous study, in which only a major saphenous vein dilation would have been a problem. ${ }^{22}$

\section{Study Strengths and Implications for Clinical Practice}

This study reveals the importance that PCV may have for all professionals who practice acupuncture, proposing a new avenue to explain the effects of this technique.

\section{Study Limitations and Recommendations for Future Research}

The limitations of the study lie in the specificity of the thermal response to the vascular stress stimuli of each individual, which hampers the uniformity of the responses between subjects. The anatomy of the area was also a challenge, due to the presence of anatomical venous structures in the subcutaneous region, which made the application of such vascular stimulation difficult.

Furthermore, it would be necessary to increase the study sample in terms of the number of subjects and to extend the analysis to other areas of the body and other AP.

\section{Conclusions}

IT is a useful imaging tool for capturing PCV. This study has shown that the PCV and the AP chosen in the sample have a certain correlation, due to the high presence of PCV in the AP. The proposed hypothesis could open new avenues to explain and facilitate theoretical understanding of the mechanisms and essence of acupuncture via the description of its treatment points. Moreover, it is worth considering IT as a method to control and monitor acupuncture.

\section{Ethical Approval \\ CEU San Pablo University.}

Conflict of Interests

The authors have no conflict of interests to declare.

\section{References}

1 Berman BM, Langevin HM, Witt CM, Dubner R. Acupuncture for chronic low back pain. N Engl J Med 2010;363(05): 454-461

2 White A, Foster NE, Cummings M, Barlas P. Acupuncture treatment for chronic knee pain: a systematic review. Rheumatology (Oxford) 2007;46(03):384-390

3 Haker E, Egekvist H, Bjerring P. Effect of sensory stimulation (acupuncture) on sympathetic and parasympathetic activities in healthy subjects. J Auton Nerv Syst 2000;79(01):52-59
4 Svedberg L, Nordahl G, Lundeberg T. Effects of acupuncture on skin temperature in children with neurological disorders and cold feet. Dev Med Child Neurol 2001;43(05):358-360

5 Dhond RP, Yeh C, Park K, Kettner N, Napadow V. Acupuncture modulates resting state connectivity in default and sensorimotor brain networks. Pain 2008;136(03):407-418

6 Hui KK, Liu J, Marina O, et al. The integrated response of the human cerebro-cerebellar and limbic systems to acupuncture stimulation at ST 36 as evidenced by fMRI. Neuroimage 2005;27 (03):479-496

7 Agarwal-Kozlowski K, Lange AC, Beck H. Contact-free infrared thermography for assessing effects during acupuncture: a randomized, single-blinded, placebo-controlled crossover clinical trial. Anesthesiology 2009;111(03):632-639

8 Zhi Wei D, Yu S, Yongqiang Z. Perforators, the Underlying Anatomy of Acupuncture Points. Altern Ther Health Med 2016;22(03):25-30

9 Taylor GI, Palmer JH. The vascular territories (angiosomes) of the body: experimental study and clinical applications. Br J Plast Surg 1987;40(02):113-141

10 Blondeel PN, Van Landuyt KH, Monstrey SJ, et al. The "Gent" consensus on perforator flap terminology: preliminary definitions. Plast Reconstr Surg 2003;112(05):1378-1383, quiz 1383, 1516, discussion 1384-1387

11 Smit JM, Klein S, Werker PM. An overview of methods for vascular mapping in the planning of free flaps. J Plast Reconstr Aesthet Surg 2010;63(09):e674-e682

12 Tenorio X, Mahajan AL, Elias B, et al. Locating perforator vessels by dynamic infrared imaging and flow Doppler with no thermal cold challenge. Ann Plast Surg 2011;67(02):143-146

13 Moreira D, Nohama P. Mapeamento Térmico nos pontos de acupuntura. Três Corações 2016;14(02):1034-1043

14 Álvarez Prats D, Carvajal Fernández Ó. Termografía en fisioterapia. En: Valera Garrido F, Minaya Muñoz F (editores). Fisioterapia Invasiva 2ª Ed. Barcelona: Elsevier España, S. L.; 2016

15 Merla A, Mattei PA, Di Donato L, Romani GL. Thermal imaging of cutaneous temperature modifications in runners during graded exercise. Ann Biomed Eng 2010;38(01):158-163

16 Ring EF, Ammer K. Infrared thermal imaging in medicine. Physiol Meas 2012;33(03):R33-R46

17 Sussmann D Acupuntura: teoría y práctica. Buenos Aires, editorial Kier S.A. 2000

18 Focks C. Atlas of acupuncture. China: Elsevier Churchilll Livingstone; 2006

19 Hildebrandt C, Raschner C, Ammer K. An overview of recent application of medical infrared thermography in sports medicine in Austria. Sensors (Basel) 2010;10(05):4700-4715

20 Garagiola U, Giani E. Use of telethermography in the management of sports injuries. Sports Med 1990;10(04):267-272

21 Estanol-Vidal B, Gutierrez-Manjarrez F, Martinez-Memije R, et al. The two faces of veno-arteriolar reflex: cutaneous vasodilatation and vasoconstriction to raise and to lower the arm. Rev Neurol 2016;62(09):403-407

22 Álvarez-Prats D, Carvajal-Fernández O, Valera Garrido F, et al. Acupuncture Points and perforating cutaneous vessels identified using infrared thermography: A cross-sectional study. Evid Based Complement Alternat Med 2019;2019:7126439

23 Yang HQ Xie SS, Hu XL, Chen L, Li H. Appearance of human meridian-like structure and acupoints and its time correlation by infrared thermal imaging. Am J Chin Med 2007;35(02):231-240

24 Mei J, Morris SF, Ji W, Li H, Zhou R, Tang M. An anatomic study of the dorsal forearm perforator flaps. Surg Radiol Anat 2013;35 (08):695-700

25 Hekner DD, Roeling TA, Van Cann EM. Perforator anatomy of the radial forearm free flap versus the ulnar forearm free flap for head and neck reconstruction. Int J Oral Maxillofac Surg 2016;45(08): 955-959

26 Itoh Y, Arai K. Use of recovery-enhanced thermography to localize cutaneous perforators. Ann Plast Surg 1995;34(05):507-511 
27 de Weerd L, Weum S, Mercer JB. The value of dynamic infrared thermography (DIRT) in perforatorselection and planning of free DIEP flaps. Ann Plast Surg 2009;63(03):274-279

28 Kimura T, Ebisudani S, Osugi I, Inagawa K. Anatomical Analysis of Cutaneous Perforator Distribution in the Forearm. Plast Reconstr Surg Glob Open 2017;5(10):e1550
29 Chubb DP, Taylor GI, Ashton MW. True and 'choke' anastomoses between perforator angiosomes: part II. dynamic thermographic identification. Plast Reconstr Surg 2013;132(06):1457-1464

30 Aoki S, Tanuma K, Iwakiri I, et al. Clinical and vascular anatomical study of distally based sural flap. Ann Plast Surg 2008;61(01): $73-78$ 